\title{
Tilbakefall av eggstokkreft og borderline tumorer i eggstokkene i Norge
}

\author{
Torbjørn Paulsen \\ Kreftregisteret, Montebello, 0310 Oslo
}

ENGLISH SUMMARY

\section{Paulsen T. Recurrence of ovarian cancer and borderline ovarian tumours in Norway.} Nor J Epidemiol 2001; 11 (2): 143-146.

Background: The 5-year relative survival for patients with ovarian cancer in Norway has improved over time, but is still less than $40 \%$. Early diagnosis and optimal therapy can hopefully better the prognosis. In order to improve the techniques of examination, treatment and follow-up of these patients, the establishment of a system for quality insurance of clinical data for cancer in Norway (NOU 20,1997) has been suggested. According to the answers of a questionnaire that was sent to the gynaecological departments in Norway in the spring of 2000, there were differences in how hospitals handle ovarian cancer patients.

Introduction: The age-standardised incidence rate for ovarian cancer has increased from 11.9 per 100000 person-years in 1957 to 13.3 per 100000 in 1997. The incidences in the Nordic countries, with the exception of Finland, are among the highest in the world. The borderline ovarian tumours (BOT) had an incidence rate of 4.8 per 100000 in the period 1970 to 1993.

Aim: The main aim of this extended registration of ovarian cancer and BOT in Norway is to better document diagnostic procedures and treatment. We will emphasise the recurrence of ovarian cancer and BOT.

Controversies: Only a few prospective protocols have been planned or carried out internationally that were randomised for different treatments of recurrent ovarian cancer. The studies that have been carried out have included only a few patients. In our project we will collect clinical information from the whole population of women with ovarian cancer and BOT in Norway. Surgery of women with recurrence of ovarian cancer in order to achieve tumour reduction is still controversial. Some authors claim that tumour reduction surgery improves the survival of these patients, but this is not proven. Some authors indicate that elderly patients may receive less surgical and chemotherapeutic treatment without obvious clinical rationale. Today we do not know which treatment of recurrence of ovarian cancer gives the longest survival and best quality of life. The incorporation of paclitaxel into first-line therapy improves the duration of progression-free survival and overall survival in women with incompletely-resected stage III and stage IV ovarian cancer. However we do not know which treatment gives the best overall survival in the case of recurrence. BOT are different from the invasive tumours of the ovary, with longer relative 5-year survival. BOT stage I has relative 5-year survival of $99 \%$ and for the advanced stages $92 \%$. Probably BOT develop through accumulation of different genetic mutations than invasive epithelial ovarian tumours.

Material and method: All women with diagnosed ovarian/tube/perinoneal cancer and BOT as primary disease or recurrence in Norway will be included in this study. About 500 women are diagnosed with ovarian cancer annually and 330 women with recurrence. The number of BOT is approximately 130 per year. A new registration form will be sent to all hospitals in Norway with gynaecological departments. The form consists of clinical and pathological data. In addition we will select paraffin-embedded microscope slides of BOT in the histological archive of the Norwegian Radium hospital; one group with primary disease and one group with recurrence. We will compare immunohistological characteristics of these two groups.

Scientific significance: The aim of the project is to improve the quality of the data and give better knowledge about course and treatment of women with recurrence of ovarian cancer and BOT in Norway.

Plan of progress: The project is estimated to take three years. The new form in the pilot-project will be in use from the middle of October 2001. The new form will be evaluated in January 2002. A new permanent form will then be worked out according to the experience from the pilot-form. After the end of the project in three years, we will further analyse the 5-year relative survival.

\section{BAKGRUNN}

I de senere år har man i enkelte regioner (f.eks. Northern Region of England) registrert kliniske data hos alle pasienter med en sykdom innenfor et geografisk område. Kunnskaper om pasientenes sykdom basert på hele populasjonen kalles "reality based medicine" eller
PACE (population adjusted clinical epidemiology) (1). En begrensning ved kliniske studier er at pasientmaterialet er selektert og dermed blir resultatene ikke representative for hele pasientpopulasjonen. Med utgangspunkt i Norsk Kreftplans tiltak åtte som omhandler etablering av et system for kvalitetsovervåking (2) og på initiativ fra Stortinget, satte Kreftregisteret i gang et 
"Forprosjekt for registrering av tilbakefall og registrering med sikte på iverksetting av et nytt melde- og overvåkningssystem". Kreftregisterets rapport om dette kom i juni 1999: "Utvidet registrering av kreftsykdom i Norge" (3). Det ble i undersøkelsen avdekket vesentlige mangler i pasientjournalene blant annet vedrørende behandlingsintensjon og ventetid. Kliniske data ved førstegangssykdom og tilbakefall registreres i liten grad av Kreftregisteret i dag.

\section{INNLEDNING}

Den aldersstandardiserte insidensraten for eggstokkkreft steg fra 11,9 per 100000 per år i 1957 til 13,3 per 100000 per år i 1997 (4). Insidensen i de nordiske landene, bortsett fra Finland, er blant de høyeste i verden (5). Hovedårsakene til eggstokkreft er ukjente, men noen risikofaktorer kjenner vi. Arv som hovedfaktor utgjør mellom 5 og 10\%, mens resten antas å være spontant forekommende tilfeller (6). Vi mener å vite at mange fødsler, amming og p-piller beskytter mot eggstokkreft. Fem-års relativ overlevelse for hele landet har bedret seg fra 1950-tallet og fram til i dag. For diagnoseperioden 1954-1958 var den 22\% (7), mens den for diagnoseperioden $1989-1993$ var 38,7\%. Overlevelsen er imidlertid den laveste blant alle kreftformene i underlivet.

Forekomsten av borderline tumorer i eggstokkene (borderline ovarian tumors, BOT) var i perioden 197019934,8 per 100.000 per år (8), dette tilsvarte 136 pasienter i 1993 (2). Fem-års relativ overlevelse for perioden 1970-1993 var 93\% for alle stadier BOT (7).

\section{MÅL}

Hovedformålet med utvidet registrering av eggstokkkreft og BOT i Norge er et ønske om å bedre dokumentasjonen av diagnostikk og behandling. Man vil legge spesiell vekt på tilbakefall. Dette vil på sikt kunne gi bedre diagnostikk, behandling og totalomsorg for pasienter med tilbakefall.

\section{Problemstillinger}

I følge Kreftregisterets spørreundersøkelse våren 2000 er det stor variasjon mellom sykehusene $\mathrm{i}$ behandlingen av tilbakefall (9). Det er gjennomført og planlagt få prospektive protokoller som har randomisert mellom ulike behandlinger for tilbakefall av eggstokkkreft (10-13). Noen få behandlingsprotokoller er satt i gang internasjonalt. De undersøkelsene som er utført hittil har inkludert få pasienter $(14,15)$. I vårt prosjekt vil man samle inn kliniske data fra hele populasjonen som får eggstokkreft og BOT i Norge.

Noen forfattere antyder at eldre kvinner ( $>75$ år) får utført mindre avanserte operasjoner og får enklere cellegiftkurer enn yngre kvinner (16). Det er fortsatt kontroversielt å operere kvinner med tilbakefall av eggstokkreft for å oppnå tumorreduksjon (17). Noen forfattere mener at tumorreduksjonskirurgi ved tilbakefall kan forlenge pasientenes overlevelse $(14,15)$.
Dette prosjektet vil bidra med kunnskaper om utredning og behandling ved tilbakefall. Videre vil vi kunne si hvordan forløpet av sykdommen blir etter at tilbakefallet er diagnostisert. Man vil spesielt kartlegge bivirkninger og komplikasjoner til behandlingen. Er disse på et akseptabelt nivå? Internasjonalt mangler det undersøkelser som tar for seg morbiditet i forbindelse med operasjoner av avansert eggstokkreft og hvilken betydning dette har for livskvaliteten til disse kvinnene (18). Hvilket funksjonsnivå har kvinnene etter avsluttet tilbakefallsbehandling i forhold til før behandling?

Vi mangler i dag kunnskaper om hvilke behandlingsmodaliteter som er de beste for kvinner med tilbakefall av eggstokkreft og BOT. Vi vet heller ikke om dagens tilbakefallsbehandling med kirurgi og cellegift gir lengre overlevelse og optimal livskvalitet. Det finnes randomiserte, prospektive undersøkelser som viser at innføringen av kombinasjonen paklitaxel og platinaforbindelser forlenger sykdomsfri og total overlevelse ved førstegangssykdom (19). Slike undersøkelser mangler ved tilbakefallsbehandling. Det er viktig at behandlingen tolereres godt uten alvorlige bivirkninger og at den gir en akseptabel livsforlengelse. En stor del av tilbakefallsbehandlingen gis som intravenøs cellegift. Undersøkelser viser at flertallet av pasientene ønsker cellegift gitt som tabletter (20). Det er viktig å avgjøre om tablettkurer kan erstatte intravenøs behandling (21-26).

BOT skiller seg fra de invasive svulstene ved at de har lengre relativ fem-års overlevelse. Tumorer i stadium I har 99\% relativ fem-års overlevelse og tumorer i avanserte stadier $92 \%$ (27). Dette tyder på at BOT er forskjellig fra invasive eggstokktumorer med hensyn til klinisk forløp. Sannsynligvis utvikler BOT seg via akkumulering av andre genetiske mutasjoner enn invasive epiteliale eggstokktumorer (28-31).

p53 mutasjoner er hyppig forekommende i invasive eggstokktumorer, men fraværende ved BOT. Hos invasive eggstokktumorer finner man "loss of heterozygosity" (LOH) i multiple områder, mens hos BOT bare i kromosom Xq. K-ras aktivering er relativt hyppig ved BOT, spesielt hos de mucinøse typene $(28,29)$.

I samarbeid med avdeling for tumorbiologi og patologi vil vi se på noen utvalgte biologiske karakteristika med immunhistokjemi-analyser (32-34). Vi mangler kunnskap om hvilke biologiske forandringer som forårsaker utvikling av BOT ved førstegangssykdom og tilbakefall.

\section{MATERIALE OG METODE}

Materialet vil omfatte alle kvinner som får eggstokk/ eggleder/bukhinnekreft/BOT som førstegangssykdom og tilbakefall i Norge i treårsperioden 2002-2004. Hvis vi antar at gjennomsnittlig $70 \%$ av alle kvinner med eggstokkreft får tilbakefall vil dette utgjøre 335 pasienter i året i tillegg til 478 nye tilfeller hvert år. Til sammen utgjør dette i overkant av 800 meldinger i året. Over tre år utgjør antall tilbakefall ca. 1000 og 
det totale antall nyoppdagede tilfeller og tilbakefall i overkant av 2400. I tillegg utgjør BOT ca. 130 pasienter per år, til sammen 390 tilfeller over tre år. I denne pasientgruppen er antall tilbakefall mer usikre, mellom 5 og 10\% for hele gruppen.

Materialet vil bestå av en nyetablert database i Kreftregisteret med tradisjonelt innsamlede data og nye kliniske data. Det er utarbeidet et nytt meldeskjema for dette med de samme opplysningene som tidligere, men med nye behandlingsdata ved førstegangssykdom og tilbakefall. Det behandlende sykehus sender inn et skjema til Kreftregisteret både ved førstegangssykdom og ved tilbakefall. Det er også viktig med bedre kliniske data vedrørende førstegangssykdom da disse data danner grunnlaget for tilbakefallsbehandlingen. Kreftregisterets spørreundersøkelse blant landets gynekologiske avdelinger om hvordan de utreder, behandler og utfører etterkontroller av kvinner med eggstokkreft danner bakgrunnen for det nye meldeskjemaet (9). Hvert enkelt sykehus vil få tilgang til data fra eget sykehus slik at de kan kvalitetssikre egen virksomhet.

Når det gjelder BOT vil man gå gjennom kodegrunnlaget til Kreftregisteret 10-15 år bakover i tid, for å se om kodingen samsvarer med dagens retningslinjer. Videre vil vi med en randomisert prosedyre ta ut histologiske snitt fra arkivet ved DNR og sammenligne immunhistokjemiske karakteristika hos en gruppe med førstegangssykdom og en gruppe med tilbakefall.

\section{VITENSKAPELIG BETYDNING}

Dette prosjektet har som mål å forbedre datakvaliteten og gi økt kunnskap om forløp, behandling og biologiske karakteristika av kvinner med tilbakefall av eggstokkreft og BOT i Norge. Prosjektet vil kunne avdekke geografiske forskjeller i utredning, behandling og oppfølging av pasientene. Det er planlagt følgende artikler i internasjonale tidsskrift:

- Evaluering av pilotprosjektet høsten 2001.

- Genetiske forandringer ved førstegangsdiagnose BOT og tilbakefall hos pasienter med og uten implantasjonsmetastaser. Det er i dag uklart hvilke biologiske forandringer som fører til BOT.

- Beskrivelse av kliniske opplysninger ved tilbakefall. Det er viktig med mer detaljerte opplysninger om tilbakefallet slik at man kan ta ut pasienter som kan ha nytte av behandling i tilbakefallssituasjonen.

- Betyr ventetiden for diagnose noe for prognosen til pasienten?

- Er det regionale forskjeller i behandlingen og påvirker dette pasientens prognose?

- Vi vil kartlegge forekomsten av bivirkninger og komplikasjoner til behandlingen av eggstokkreft i Norge. I dag vet vi lite om forekomsten av bivirkninger og komplikasjoner og hvilken behandling som gis.

\section{FRAMDRIFTSPLAN}

Vi vil gjennomføre et tre-årsprosjekt der man etter det første året med datainnsamling vil starte evaluering av innkomne data. Høsten 2001 vil gå med til pilotprosjektet: "Utprøving av meldeskjema og meldelogistikk". Det nye meldeskjemaet i pilotprosjektet vil taes i bruk medio oktober 2001 og evalueres i januar 2002. Det vil da utarbeides et endelig meldeskjema på grunnlag av erfaringene fra pilotregistreringen.

Etter prosjektets slutt vil de innsamlede data sammen med data fra videre registrering danne grunnlaget for ytterligere analyser, som fem-års overlevelse.

\section{REFERANSER}

1. Charlton BG, Taylor PR, Proctor SJ. The PACE (population-adjusted clinical epidemiology) strategy: a new approach to multi-centred clinical research. QJM 1997; 90: 147-51.

2. Norges offentlige utredninger. Omsorg og kunnskap. Norsk kreftplan. NOU 1997: 20. Oslo: Statens forvaltningstjeneste, Seksjon statens trykning, 1997.

3. Iversen T. Utvidet registrering av kreftsykdom i Norge. Forprosjekt for registrering av tilbakefall og registrering med sikte på iverksetting av et nytt melde- og overvåkingssystem. Rapport til Institutt for epidemiologisk kreftforskning. Kreftregisteret, 1999.

4. Cancer in Norway 1997. Kreftregisteret 2000.

5. Bjørge T, Engeland A, Hansen S, Tropé CG. Ovariecancer og borderline tumorer. Tidsskr Nor Lageforen 1998; 118: 2471-5.

6. Dørum A, Heimdal K, Løvslett K, Kristensen G, Hansen LJ, Sandvei R, et al. Prospectively detected cancer in familial breast/ovarian cancer screening. Acta Obstet Gynecol Scand 1999; 78: 906-11.

7. Bjørge T, Engeland A, Hansen S, Tropé CG. Prognosis of patients with ovarian cancer and borderline tumours diagnosed in Norway between 1954 and 1993. Int J Cancer 1998; 75: 663-70.

8. Bjørge T, Engeland A, Hansen S, Tropé CG. Trends in the incidence of ovarian cancer and borderline tumours in Norway, 1954-1993. Int J Cancer 1997; 71: 780-6.

9. Paulsen T, Kærn J, Kjærheim K, Norstein J, Onsrud M. Utredning, behandling og etterkontroll av eggstokkreft i Norge. Tidsskr Nor Lageforen 2001, under trykking. 
10. Kuhn W, Schmalfeldt B, Pache L, Spathe K, Ulm K, Renziehausen K, et al. Disease-adapted relapse therapy for ovarian cancer: results of a prospective study. Int J Oncol 1998; 13: 57-63.

11. Bolis G, Scarfone G, Giardina G, Villa A, Mangili G, Melpignano M, et al. Carboplatin alone vs carboplatin plus epidoxorubicin as second-line therapy for cisplatin- or carboplatin-sensitive ovarian cancer. Gynecol Oncol 2001; 81: 3-9.

12. Markman M. Second-line therapy for potentially platinum-sensitive recurrent ovarian cancer: what is optimal treatment? Gynecol Oncol 2001; 81: 1-2.

13. Markman M, Bookman MA. Second-line treatment of ovarian cancer. Oncologist 2000; 5: 26-35.

14. Zang RY, Zhang ZY, Li ZT, Chen J, Tang MQ, Liu Q, et al. Effect of cytoreductive surgery on survival of patients with recurrent epithelial ovarian cancer. J Surg Oncol 2000; 75: 24-30.

15. Eisenkop SM, Friedman RL. The role of secondary cytoreductive surgery in the treatment of patients with recurrent epithelial ovarian carcinoma. Cancer 2000; 88: 144-53.

16. van Rijswijk RE, Vermorken JB. Drug therapy for gynaecological cancer in older women. Drugs Aging 2000; 17: 13-32.

17. Tropé C, Paulsen T, Baekelandt M, Makar A. Kontroverser ved kirurgisk behandling av avansert ovarialcancer. Tidsskr Nor Lageforen 2000; 120: 824-30.

18. Covens AL. A critique of surgical cytoreduction in advanced ovarian cancer. Gynecol Oncol 2000; 78: 26974.

19. McGuire WP, Hoskins WJ, Brady MF, Kucera PR, Partridge EE, Look KY, et al. Cyclophosphamide and cisplatin compared with paclitaxel and cisplatin in patients with stage III and stage IV ovarian cancer. $N$ Engl J Med 1996; 334: 1-6.

20. Stinson TJ, Calhoun E, Yang T, Lurain JR, Bennett CL. Cost analysis of second-line therapies for platinumrefractory ovarian cancer: reimbursement dilemmas for Medicare patients. Cancer Invest 1999; 17: 559-65.

21. Nicoletti MI, Colombo T, Rossi C, Monardo C, Stura S, Zucchetti M, et al. IDN5109, a taxane with oral bioavailability and potent antitumor activity. Cancer Res 2000; 60: 842-46.

22. Verschraegen CF, Gupta E, Loyer E, Kavanagh JJ, Kudelka AP, Freedman RS, et al. A phase II clinical and pharmacological study of oral 9-nitrocamptothecin in patients with refractory epithelial ovarian, tubal or peritoneal cancer. Anticancer Drugs 1999; 10: 375-83.

23. Vergote I, Himmelmann A, Frankendal B, Scheistrøen M, Vlachos K, Tropé C. Hexamethylmelamine as second-line therapy in platin-resistant ovarian cancer. Gynecol Oncol 1992; 47: 282-6.

24. Hilger RA, Jacek G, Oberhoff C, Kredtke S, Baumgart J, Seeber S, et al. Investigation of bioavailability and pharmacokinetics of treosulfan capsules in patients with relapsed ovarian cancer. Cancer Chemother Pharmacol 2000; 45: 483-8.

25. Rose PG, Rodriguez M, Waggoner S, Greer BE, Horowitz IR, Fowler JM, et al. Phase I study of paclitaxel, carboplatin, and increasing days of prolonged oral etoposide in ovarian, peritoneal, and tubal carcinoma: a gynecologic oncology group study. J Clin Oncol 2000; 18: 2957-62.

26. Rose WC, Lee FY, Golik J, Kadow J. Preclinical oral antitumor activity of BMS-185660, a paclitaxel derivative. Cancer Chemother Pharmacol 2000; 46: 246-50.

27. Kurman RJ, Trimble CL. The behavior of serous tumors of low malignant potential: are they ever malignant? Int J Gynecol Pathol 1993; 12: 120-7.

28. Teneriello MG, Ebina M, Linnoila RI, Henry M, Nash JD, Park RC, et al. p53 and Ki-ras gene mutations in epithelial ovarian neoplasms. Cancer Res 1993; 53: 3103-8.

29. Pieretti M, Cavalieri C, Conway PS, Gallion HH, Powell DE, Turker MS. Genetic alterations distinguish different types of ovarian tumors. Int J Cancer 1995; 64: 434-40.

30. Cheung VG, Nowak N, Jang W, Kirsch IR, Zhao S, Chen XN, et al. Integration of cytogenetic landmarks into the draft sequence of the human genome. Nature 2001; 409: 953-8.

31. Cheng PC, Gosewehr JA, Kim TM, Velicescu M, Wan M, Zheng J, et al. Potential role of the inactivated X chromosome in ovarian epithelial tumor development. J Natl Cancer Inst 1996; 88: 510-8.

32. Ree AH, Florenes VA, Berg JP, Mælandsmo GM, Nesland JM, Fodstad O. High levels of messenger RNAs for tissue inhibitors of metalloproteinases (TIMP-1 and TIMP-2) in primary breast carcinomas are associated with development of distant metastases. Clin Cancer Res 1997; 3: 1623-8.

33. Ree AH, Bjørnland K, Brunner N, Johansen HT, Pedersen KB, Aasen AO, et al. Regulation of tissuedegrading factors and in vitro invasiveness in progression of breast cancer cells. Clin Exp Metastasis 1998; 16: $205-15$.

34. Ree AH, Mælandsmo GM, Fodstad O. Regulation of matrix metalloproteinase-1 and tissue inhibitor of metalloproteinase-1 in MCF-7 cells: comparison with regulatory mechanisms of pS2 expression. Clin Exp Metastasis 1996; 14: 381-8. 